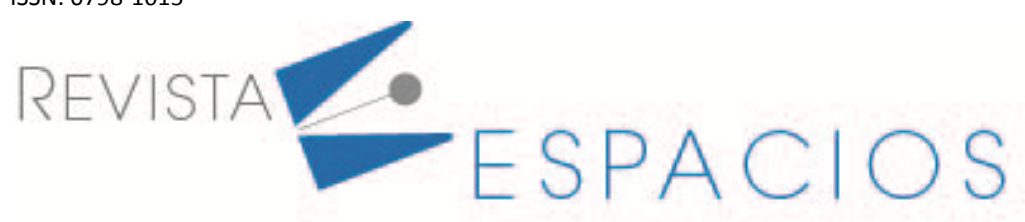

\title{
Memes para una educación literaria o «Allí donde las palabras no llegan, llega un meme»
}

\section{Memes for a literary education or "Where words do not reach, a meme arrives»}

\author{
PARRADO-COLLANTES, Milagrosa ${ }^{1}$ \\ ROMERO-OLIVA, Manuel F. ${ }^{2}$ \\ HEREDIA-PONCE, Hugo ${ }^{3}$
}

\begin{abstract}
Resumen
Esta investigación está incluida dentro de una perspectiva de aplicación didáctica sobre las posibilidades cognitivas del empleo de memes literarios, la competencia semiótica y un carácter hipertextual e hipermedial. Su objetivo principal es analizar la relación entre la competencia literaria del alumnado y los memes literarios en el aula de Literatura Infantil y Fomento de la Lectura $(\mathrm{N}=133)$. Los resultados se categorizaron en: uso de plataformas y lecturas digitales; y competencia literaria, disfrute y relaciones intertextuales de los memes literarios.

Palabras clave: memes, educación literaria, fomento de la lectura

Abstract

This research is included within a perspective of didactic application on the cognitive possibilities of the use of literary memes, the semiotic competence and a hypertextual and hypermedial character. Its main objective is to analyse the relationship between literary competence of the students and the literary memes in the classroom of Children Literature and Reading Promotion $(\mathrm{N}=133)$. The results have been categorised into: use of platforms and digital readings; and literary competence, enjoyment and intertextual relations of the literary memes.
\end{abstract}

key words: memes, literary education, reading promotion

\section{Introducción}

Es indudable que, en la actualidad, los memes forman parte de la vida mediática de todos y que, además, se han incorporado a nuestra cotidianeidad como una forma más de comunicación. Ya en 2016, Beltrán Pellicer anunciaba categóricamente "Los memes están de moda" (p. 129), una moda que parece que ha llegado para quedarse.

\footnotetext{
${ }^{1}$ Profesora e investigadora. Departamento de Didáctica de la Lengua y la Literatura. Universidad de Cádiz. milagrosa.parrado@uca.es

2 Profesor e investigador. Departamento de Didáctica de la Lengua y la Literatura. Universidad de Cádiz.manuel.franciscoromero@uca.es

${ }^{3}$ Profesor e investigador. Departamento de Didáctica de la Lengua y la Literatura. Universidad de Cádiz. hugo.heredia@uca.es
} 
Desde esta perspectiva, este estudio se plantea dentro de un análisis de nuevas herramientas para el desarrollo de la competencia semiológica, mediática e hipertextual en relación directa con el desarrollo de la competencia literaria en maestros en formación inicial, bajo el paraguas de nuevas estrategias para una educación literaria.

El uso de memes con referencias culturales -en general- y literarias -en particular- es un elemento vehicular y un buen punto de partida para acercar el hecho literario al alumnado que, frecuentemente, sostiene creencias y actitudes muy negativas con respecto a la enseñanza de literatura, argumentando, quizá, la lejanía en relación con sus focos de interés. Este no es un hecho aislado de los jóvenes en formación literaria media (Secundaria y Bachillerato), sino que también se constata en el alumnado universitario, en general, y, en particular, en nuestra muestra de población para este estudio, los maestros en formación, aspecto en el que se ha hecho hincapié en diferentes estudios (Munita, 2013 y 2016; Romero y Jiménez, 2014; Romero y Trigo, 2018; Romero y Jiménez, 2019).

\subsection{Los memes}

El término meme aparece por primera vez en la obra de Dawkins, titulada The Selfish Gene (El gen egoísta) en 1976; en ella, el autor diserta sobre la teoría de la evolución. Del concepto de meme, podemos leer:

We need a name for the new replicator, a noun that conveys the idea of a unit of cultural transmission, or a unit of imitation. 'Mimeme' comes from a suitable Greek root, but I want a monosyllable that sounds a bit like 'gene'. I hope my classicist friends will forgive me if I abbreviate mimeme to meme (1989, $\mathrm{p}$. 192).

En general, y en palabras de Beltrán Pellicer (2016), los memes son “imágenes, bien sean fotografías o dibujos, que vienen acompañadas de un texto y que, en conjunto, constituyen un chiste" (p. 129). En un intento de caracterización, podemos señalar algunas características comunes, tales como: su evolución (los memes surgen y mutan en otros memes diferentes, cambiando su temática, por ejemplo); son imágenes virales y fácilmente propagables; surgen, es decir, un meme no tiene una autoría definida. Estas características que hemos reunido, también son señaladas por Dawkins (1989):

Examples of memes are tunes, ideas, catch-phrases, clothes fashions, ways of making pots or of building arches. Just as genes propagate themselves in the gene pool by leaping from body to body via sperms or eggs, so memes propagate themselves in the meme pool by leaping from brain to brain via a process which, in the broad sense, can be called imitation. If a scientist hears, or reads about, a good idea, he passes it on to his colleagues and students. He mentions it in his articles and his lectures. If the idea catches on, it can be said to propagate itself, spreading from brain to brain (p. 192).

Aterrizando en el carácter memético para una comunicación, partiremos del concepto de competencia semiológica, mediática e hipertextual (Prado, 2011) que se ve reiterado por Lomas (1999), quien ya advertía de la necesidad de adquirir una competencia semiológica "que permita el adecuado uso e interpretación de los mensajes procedentes de los medios de comunicación" (p. 273); en este caso, relacionamos esa interpretación de la que habla Lomas con los memes a través de las redes sociales. A este respecto, y para que la adquisición de esta competencia sea efectiva se exige "el conocimiento del modo en que cada discurso utiliza los materiales lingüísticos e iconográficos, una identificación de la intención comunicativa de quien construye el mensaje [...]" (Prado, 2011, p. 382).

Por su parte, y en sintonía con la ampliación de la competencia comunicativa en una vertiente semiológica, Pérez Tornero (2000) habla de competencia mediática e hipermedia o Contín (2011) que habla directamente de competencia hipertextual.

El proceso para esa competencia mediática se traslada a la "alfabetización hipermedial" en el sentido de 
motivar a los individuos a pasar menos tiempo consumiendo medios de comunicación en estado letárgico y a activar mecanismos disparadores o ciertos tipos de mensajes y contenidos que harán que el niño o joven preste atención y así podrán, con más calma y atención, atender y escudriñar la validez y la utilidad de un determinado mensaje (p. 153).

Por su parte, Chaverra (2008) incide en que "una herramienta de escritura hipermedial le ofrece al lectorescritor no solo nuevas posibilidades para exponer su pensamiento o expresar mejor las complejas interrelaciones que tienen las ideas en su mente" (p.31).

En esta línea, incidiendo y finalizando con el carácter hipermedial, relacionamos la red memética en correlación con su carácter hipertextual, en el sentido en que se transfigura como escritura no lineal, nos referimos a una relación de información, donde el usuario puede decidir qué enlaces elegir de entre las asociaciones que se le presentan. Hablamos de un texto que puede leerse y releerse de manera diferente, con enlaces que no siguen un orden preestablecido e incluso podemos hablar de textos que no tienen ni un principio ni un fin determinado (Zamora, 2016, p.4).

Además, es importante, según la autora, regular los procesos cognitivos para poder seleccionar y relacionar los hipertextos en torno a una representación mental coherente.

Esta aproximación teórica según la mira caleidoscópica de la competencia semiótica y el carácter hipertextual e hipermedial se ajusta perfectamente a esta propuesta memética para una educación literaria: en la línea de los memes para una educación literaria, a pesar de que la memética ha caído, a veces -y hemos de admitirlo-, en propagar chistes banales y, en ocasiones, de mal gusto, podemos encontrar en páginas específicas un material muy valioso para el acercamiento de la historia, el carácter, la obra o simplemente anécdotas de los autores más consagrados en la historia de la literatura. Para entender mejor este material del que hablamos, podemos poner como ejemplos el gran éxito de páginas en distintas redes sociales, como Memes literarios o Memes culturales. En este caso, los ejemplos también son infinitos, pero vemos como los creadores de estos memes usan memes ya anteriores, haciendo referencia a series de televisión muy famosas y los entremezclan con personajes literarios en el top del canon, como Borges, Dante, Calderón de la Barca o Lorca. Como vemos, los resultados son hilarantes a la par que útiles. Estamos seguros de que una muy buena parte del alumnado con el que trabajamos ha visto o son audiencia habitual de Los Simpsons o de la archiconocida serie basada en las novelas de George R.R. Martin, Juego de Tronos. Esta mezcla, tomando como punto de partida algún meme en especial, puede ser un soporte muy útil, a la hora de introducir al autor que tenemos que impartir en el momento.

Para ilustrar un poco más el alcance de estas imágenes supersónicas relacionadas con la literatura, haremos referencia al artículo publicado en Verne donde se entrevista a estos jóvenes que han revolucionado el panorama cultural memético literario actual.

En 2012 tres jóvenes mexicanos abrieron una página en Facebook para compartir su pasión por las letras y uno que otro cuento de su autoría. Mario, Jonathan y Alegría, originarios de Jalisco, supieron que llamar la atención de los usuarios de la red social no sería fácil, por eso decidieron hacer el contenido más digerible: así nació Memes Literarios, un espacio en donde libros y autores son transformados en memes para compartir pequeños fragmentos de literatura (y humor) en redes sociales. Cuatro años después la página cuenta con más de 800.000 seguidores en Facebook y más de 9.000 en Twitter (Mulato, 2016).

Todas estas propuestas y líneas de investigación, en definitiva, conforman lo que Tabernero (2007) denomina como "una intertextualidad heterorreferencial, de la mano, como no podía ser de otro modo, de la imagen tal 
como se corresponde a un nuevo receptor, el del siglo XXI" (p.59). Concluyendo este punto, los memes podrían ser un buen punto de partida para poder acceder a la literatura como puertas de acceso a estos otros textos 0 en palabras de Tabernero (2007):

Son propuestas que requieren una mayor colaboración del receptor en la construcción de significados y que, al fin y la postre, dibujan un lector sin fronteras cronológicas, un lector que se adentra en lo desconocido para dotar de sentido a lo que comienza a interpretar. Se trata de forjar un itinerario de progresión combinado con la intertextualidad autorreferencial de la que es conveniente no abusar puesto que puede convertirse en una propuesta excesivamente "amable" con un lector en formación (pp. 60-61).

\section{Metodología}

Tras estas primeras consideraciones teóricas, establecemos un objetivo general, además de algunos objetivos específicos e hipótesis que recogemos en el siguiente cuadro resumen -Tabla 1-:

Tabla 1

Relación entre las dimensiones de estudio, objetivos e hipótesis

Objetivo principal: analizar la relación entre la competencia literaria del alumnado y los memes literarios en el aula de Literatura Infantil y Fomento de la Lectura

\begin{tabular}{|c|c|c|}
\hline Dimensiones & Objetivos & Hipótesis \\
\hline $\begin{array}{l}\text { D.1. Autoconcepto como } \\
\text { lector y uso de plataformas y } \\
\text { lecturas digitales }\end{array}$ & $\begin{array}{l}\text { O.1. Determinar si el } \\
\text { alumnado consume } \\
\text { plataformas y lecturas } \\
\text { digitales }\end{array}$ & $\begin{array}{l}\text { H.1. Pese a que el alumnado prefiere la lectura en } \\
\text { papel, hace uso de las redes sociales y comparte } \\
\text { memes de manera asidua }\end{array}$ \\
\hline $\begin{array}{l}\text { D.2. Competencia literaria, } \\
\text { disfrute y relaciones }\end{array}$ & $\begin{array}{l}\text { O.2. Indagar el nivel de } \\
\text { competencia literaria del }\end{array}$ & $\begin{array}{l}\text { H.2. La competencia literaria del alumnado no está } \\
\text { desarrollada como debiera, ya que, en el proceso de } \\
\text { interacción con los memes literarios, no se } \\
\text { decodifican los hipotextos e hipertextos. }\end{array}$ \\
\hline $\begin{array}{l}\text { intertextuales de los memes } \\
\text { literarios }\end{array}$ & $\begin{array}{l}\text { alumnado a partir de los } \\
\text { memes literarios }\end{array}$ & $\begin{array}{l}\text { Las dificultades de acceso al disfrute de los memes es } \\
\text { menor por sus carencias en el reconocimiento de } \\
\text { relaciones del intertexto lector y del intertexto } \\
\text { cultural }\end{array}$ \\
\hline
\end{tabular}

Fuente: realización propia

\subsection{Contexto y participantes}

La investigación se llevó a cabo en el segundo semestre del curso 2019-2020. La encuesta se realizó a dos grupos del cuarto y último curso del Grado en Maestro en Educación Infantil, de la asignatura Literatura Infantil y Fomento de la Lectura de la Universidad de Cádiz, es decir, este alumnado se corresponde con maestros en formación inicial ( $N=133)$.

\subsection{Diseño de la investigación}

Para este estudio, se ha preferido una investigación de corte mixta. Este tipo

implica un conjunto de procesos de recolección, análisis y vinculación de datos cuantitativos y cualitativos en un mismo estudio o una serie de investigaciones para responder a un planteamiento del problema [...]no es reemplazar a la investigación cuantitativa ni a la investigación cualitativa, sino utilizar las fortalezas de ambos tipos de indagación, combinándolas y tratando de minimizar sus debilidades potenciales (Hernández Sampieri, 214, p. 532) 
Las preguntas se dividen en dos partes que se correlacionan con los ámbitos de estudio que hemos detallado en correlación con los objetivos e hipótesis -Tabla 2-, la primera consta de preguntas cerradas y abiertas, divididas así:

Tabla 2

Relación entre las dimensiones de estudio

y los ámbitos de estudio del cuestionario

\begin{tabular}{|c|c|c|c|}
\hline $\begin{array}{l}\text { Dimensiones de } \\
\text { estudio }\end{array}$ & Valores & Bloques & $\begin{array}{l}\text { Número de } \\
\text { preguntas }\end{array}$ \\
\hline \multirow{4}{*}{1} & 1 & Lectura y su consumo en los distintos soportes & 4 \\
\hline & 2 & Concepto de meme y su uso & 1 \\
\hline & 3 & Concepción social de la memética & 2 \\
\hline & 4 & $\begin{array}{l}\text { Concepción de los memes en el ámbito educativo y el fomento } \\
\text { de la lectura }\end{array}$ & 3 \\
\hline 2 & 5 & $\begin{array}{l}\text { Relaciones de intertextualidad literaria y cultural de los memes } \\
\qquad \text { y disfrute }\end{array}$ & 2 (por cada meme) \\
\hline
\end{tabular}

Fuente: realización propia

Para el estudio de la segunda parte de la encuesta, se partió de cinco memes literarios, tres de carácter intertextual y dos de reflexión metaliteraria. A continuación, describimos e ilustramos dichos memes: en el primero se pone de relieve la diatriba sobre los clásicos; en el segundo se mezcla una imagen de Darth Vader con una "calavera" de un soldado imperial y debajo aparece la famosa cita de Hamlet "ser o no ser"; el tercero hace referencia a la clasificación tradicional de tipos de poetas; en el cuarto aparece la portada de un libro, con un puñal, donde se puede leer "Bodas de sangre de George R.R. Martin", haciendo alusión al clásico español de Lorca, en correlación con el capítulo de la serie Juego de Tronos "La boda roja"; por último, en el quinto meme se realiza una correlación con el capítulo de la obra clásica universal Don Quijote de la Mancha y una popularizada escena de la reciente película española de Netflix, El hoyo.

En este caso y para este estudio nos centraremos en el de la reflexión metaliteraria, cuyo análisis enfocaremos en las relaciones culturales de los memes y su nivel de disfrute.

Por otra parte, y debido a su complejidad, describimos la categorización de las respuestas acerca del nivel de estudio dos: las relaciones de intertextualidad literaria y cultural de los memes literarios y su nivel de disfrute:

- ¿Qué te ha sugerido este meme? Puedes hacer referencia a cualquier cuestión cultural o no que se te ocurra-Tabla 3-

Tabla 3

Categorización del nivel de intertextualidad inferida

\begin{tabular}{cl}
\hline № & \multicolumn{1}{c}{ Categoría } \\
\hline 4 & Realiza un ejercicio correcto de intertextualidad \\
3 & No se observa una relación clara en su respuesta \\
2 & No se aprecia la relación respecto al hipotexto \\
1 & Responde de manera negativa \\
0 & No responde \\
\hline
\end{tabular}

Fuente: realización propia

- ¿ ¿Te ha recordado a algo que hayas leído o estudiado con anterioridad? En caso afirmativo, justifica tu respuesta. -Tabla 4- 
Tabla 4

Categorización del nivel

de intertextualidad inferida

\begin{tabular}{cl}
\hline № & \multicolumn{1}{c}{ Categoría } \\
\hline 4 & Realiza un ejercicio correcto de intertextualidad \\
3 & No se observa una relación clara en su respuesta \\
2 & No se aprecia la relación respecto al hipotexto \\
1 & Responde de manera negativa \\
0 & No responde \\
\hline &
\end{tabular}

Fuente: realización propia

- Tras este meme, puedo decir que he disfrutado: Nada-poco-bastante-mucho. Indica la razón de tu respuesta. -Tabla 5-

Tabla 5

Categorización del nivel de competencia literaria en relación con el disfrute

\begin{tabular}{lll}
\hline \multicolumn{1}{c}{ Valores } & \multicolumn{1}{c}{ Niveles de disfrute } & \multicolumn{1}{c}{$\begin{array}{c}\text { Decodificación según la } \\
\text { competencia literaria }\end{array}$} \\
\hline 4 (valor máximo) & Disfruta con la lectura & Competencia literaria \\
3 (valor positivo) & $\begin{array}{l}\text { Se siente identificado con la } \\
\text { lectura }\end{array}$ & $\begin{array}{l}\text { Activan conocimientos, ideas } \\
\text { y experiencias previas }\end{array}$ \\
2 (valor medio) & Entiende la lectura & Plano del significado \\
1 (valor bajo) & No disfruta de la lectura & Actitud negativa hacia la \\
0 (valor negativo) & porque... & lectura \\
\hline & No responde & No se verifica \\
\hline
\end{tabular}

\section{Resultados}

A tenor de esta organización, presentamos los resultados obtenidos a partir de la encuesta realizada a los informantes ( $\mathrm{N}=133)$. Para ello, nos detendremos en las dimensiones de estudio y los valores descritos con anterioridad: el valor uno, dos, tres y cuatro, están relacionados con la dimensión autoconcepto como lector y uso de plataformas y lecturas digitales; el valor cinco se vincula con el bloque Competencia literaria, disfrute y relaciones intertextuales de los memes literarios.

\subsection{Valor 1: lectura y su consumo en los distintos soportes}

Con respecto al primer valor, observamos que en la pregunta "Me gusta leer", los resultados se polarizan entre los indicadores "bastante" (36,8 \%) y "algo" (36,8 \%) -Figura 1- 
Figura 1

Resultados de "Me gusta leer"

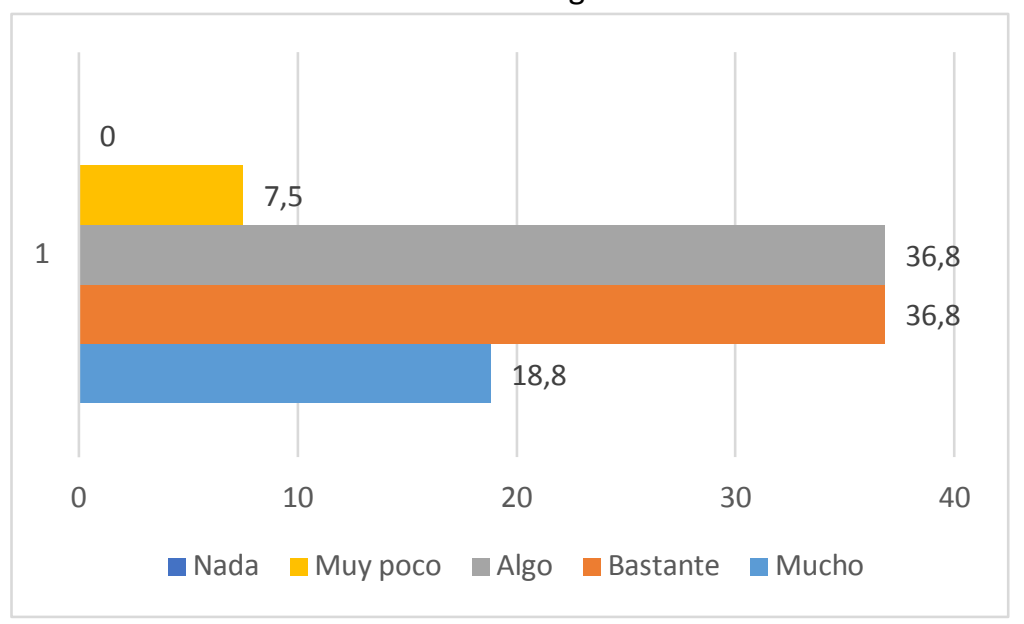

Fuente: realización propia

Por otra parte, al preguntar por la frecuencia de lectura en el tiempo libre de los informantes, los resultados se aglutinan en los ítems "alguna vez al mes" (24,8 \%); "una o dos veces por semana" (21,1 \%) y "alguna vez por semestre" (20,3\%). Es reseñable, tratándose de maestros en formación inicial, que solo un $3 \%$ de los informantes señale leer el ítem "todos los días" y un 12,8 \% indique "casi nunca" -Figura 2-

Figura 2

Resultados de "Leo libros en mi tiempo libre"

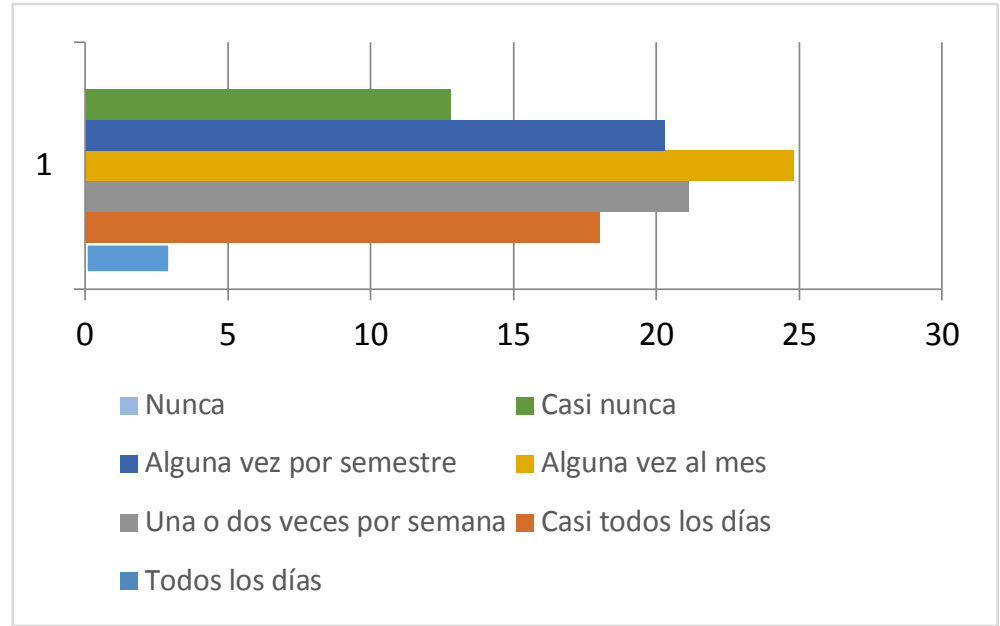

Fuente: Realización propia

Con respecto al consumo de lecturas en los distintos formatos, observamos que, en general, los resultados están bastante repartidos en los tres primeros escalafones: nunca, casi nunca y algunas veces.

En este sentido, los resultados más significativos se centran en que, de manera negativa, el alumnado opta por la escala "nunca" en un $60 \%$ a la hora de elegir APP literarias y, en relación con la elección de libros digitales, estos señalan "casi nunca" con un $44 \%$. El resultado más positivo que destacamos se encuentra en que este alumnado hace uso "frecuentemente" de los periódicos digitales un 32 \% y de los foros y chats públicos y/o privados un $25 \%$-Figura 3- 
Figura 3

Resultados de la lectura

en formatos digitales

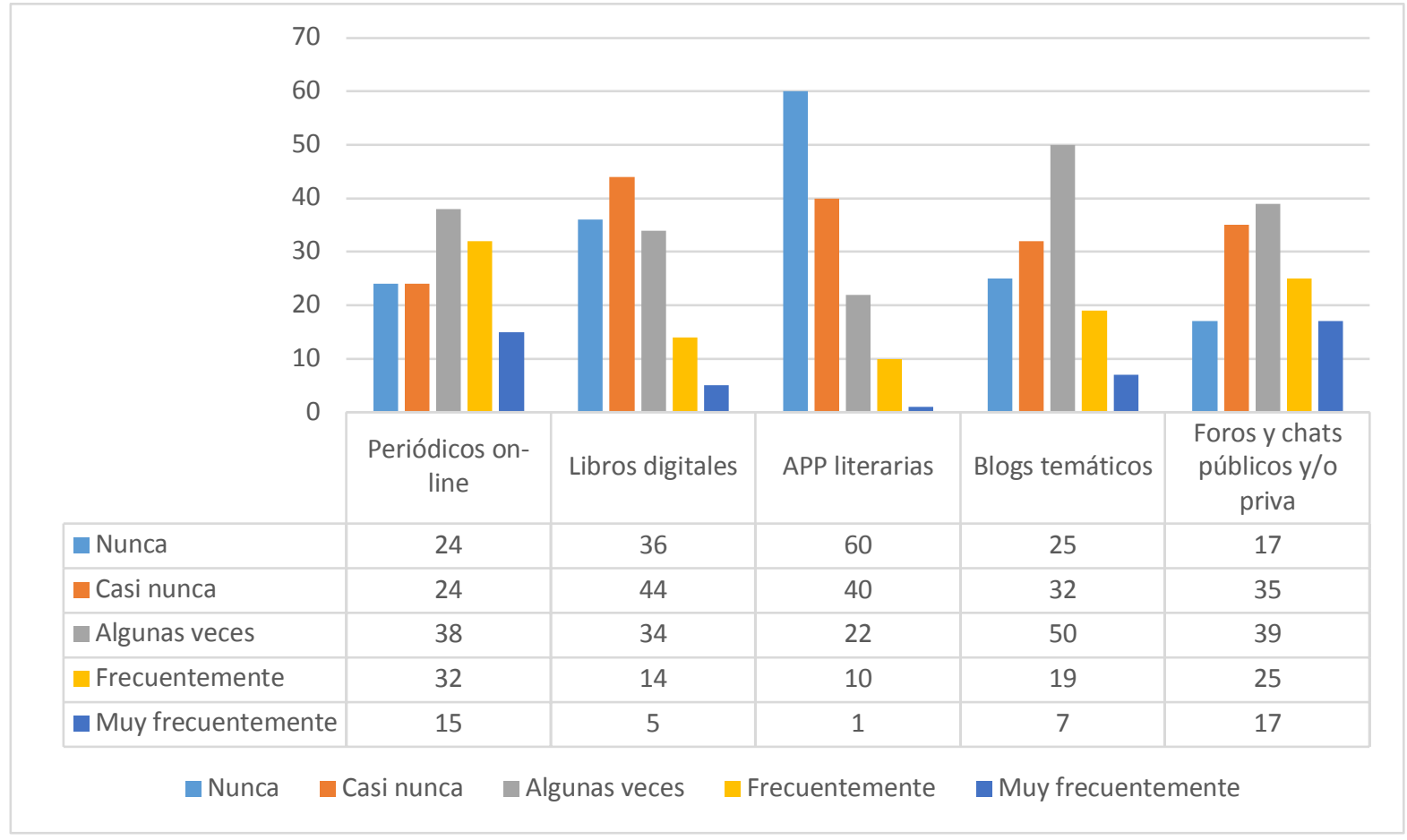

Fuente: Realización propia

\subsection{Valor 2: concepto de meme y su uso}

En el segundo valor de estudio, pedimos a los informantes que definieran qué era para ellos un meme. Hemos categorizado sus respuestas según las ideas más repetidas. Reproducimos aquí los porcentajes -representados en el gráfico 4- : chiste/ broma / divertir /hacer gracia (66,16\%); imagen (59,4 \%); texto (24\%); sarcasmo / ironía (22,5\%); cotidiano / actualidad (21,9\%); redes sociales / Internet (21\%); otras (GIF, vídeos...) (13,5\%); viral (6,8 $\%)$; cultural (6\%); temas variados (4,5\%); descripción gráfica (3\%); social, identificación personal, literatura y pedagógico (2,2 \%); imitación (1,5\%); provocar, crítica y caricatura $(0,7 \%)$. De estos conceptos destacamos algunas definiciones que consideramos interesantes y que ilustran este listado: "se entienden culturalmente por la mayoría de personas (INF _ 34)"; "Comparación graciosa sobre algún aspecto de la realidad que ha ocurrido (cotidiano o formal) puede ser a nivel social, cultural ... y solo aquellas personas que lo saben interpretar lo comprenden" (INF _ 42); "Una manera de deleitar pensamientos e ideas" (INF _ 44); "Situación clásica caracterizada hacia la burla" (INF_116); "Un meme es un contenido que refleja las meteduras de patas, en otras palabras, la ausencia de cultura en diferentes temas de los personajes públicos de nuestro país" (INF _ 74); "Allí donde las palabras no llegan, llega un meme" (INF _ 80) -Figura 4- 
Figura 4

Categorización de la

definición de meme

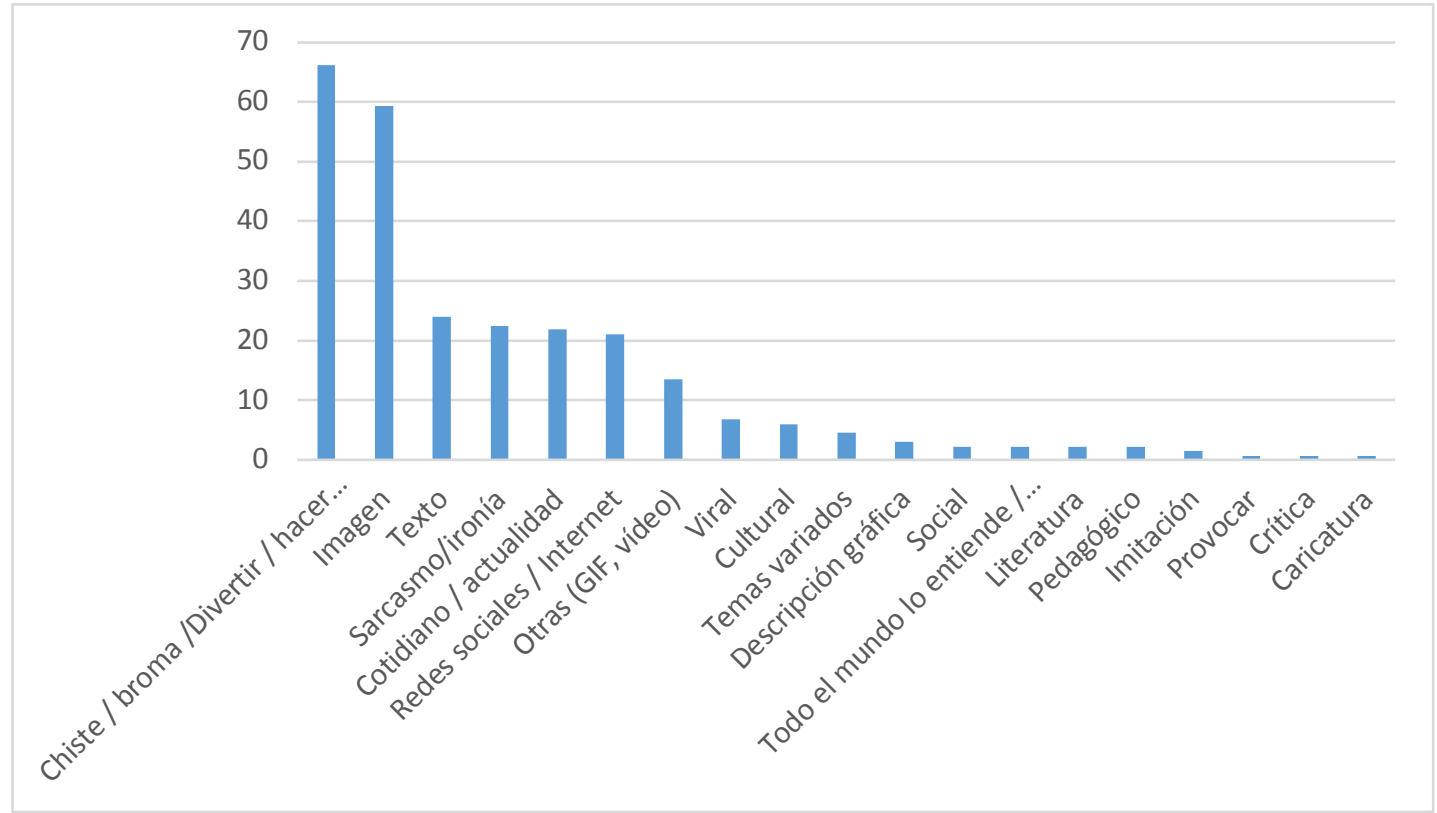

Fuente: Realización propia

\subsection{Valor 3: concepción social de la memética}

Con respecto a la concepción social de la memética, observamos una tendencia al alza en el grado 5 (completamente de acuerdo) con un 36,8 \% en relación con la pregunta de si comparten memes en los usos sociales en los que participan, aunque también este resultado tiene una inclinación ascendente en la escala 3 (algo de acuerdo) con un $25,6 \%$.

Relativo a si consideran que los memes son de uso informal, las respuestas se concentran en las categorías 3 (algo de acuerdo), con un 32, 3 \% y 4 (bastante de acuerdo), con un 36,1\%, aunque solo un 0,8 \% señala el nivel 1 (nada de acuerdo) -Figura 5-

Figura 5

Resultados de "Me gusta compartir memes en los usos sociales en los que participo" y "Considero que los memes son de uso informal"

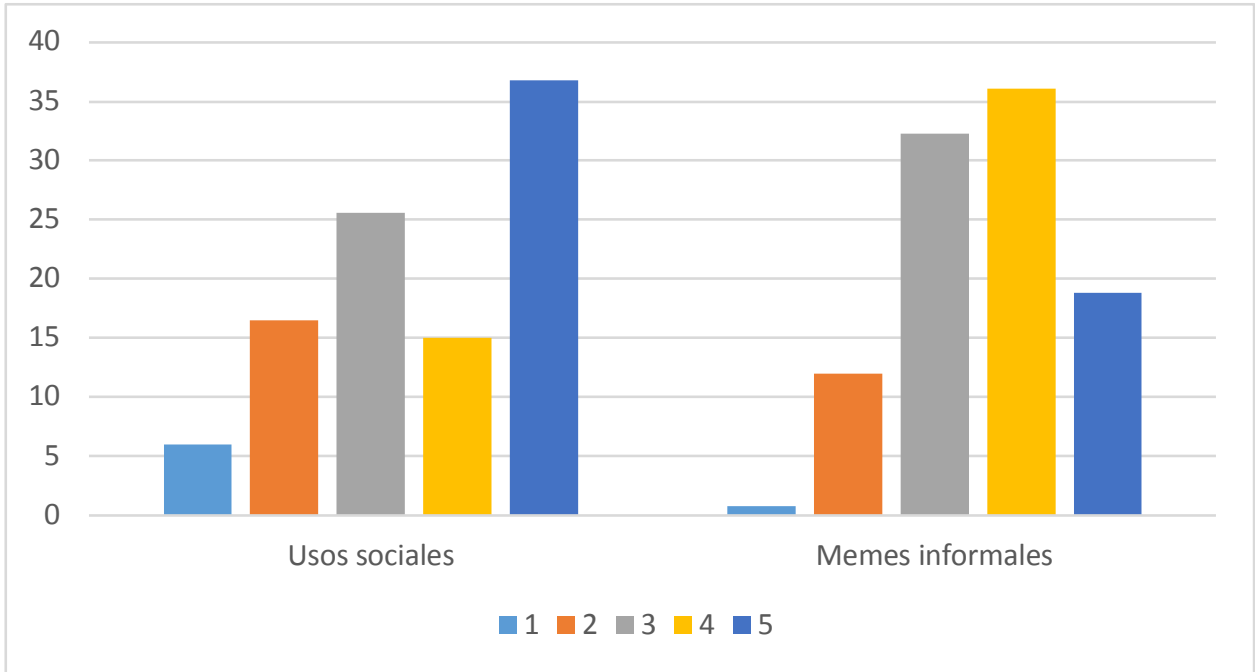

Fuente: Realización propia 


\subsection{Valor 4: concepción de los memes en el ámbito educativo y el fomento de la lectura}

A razón del valor sobre la relación entre la educación y el fomento de la lectura y el uso de memes, podemos decir que, en líneas generales, las respuestas de las tres preguntas se aglutinan en la escala 3 (algo de acuerdo). Esta concentración puede ser debido a que los informantes son maestros en formación del Grado en Educación Infantil, con lo que podrían encontrar este rango de edad más difícil a la hora de emplear memes. Constatamos esta premisa en aseveraciones como: "No he usado memes nunca, ya que mi alumnado, hasta el momento, ha sido de 3 años, por lo que no conocen mucho la cultura, y puede ser difícil su comprensión. Sin embargo, pienso que estos memes podrían adaptarse o ser creados directamente para edades tempranas" (INF _ 60); "En mi opinión creo que son buena idea para que los niños y niñas entiendan mejor un concepto, pero sí que es verdad que no se utiliza frecuentemente" (INF_ 11); “Quizás en infantil sea un poco más difícil pero se trata de un medio visual bastante atractivo para el alumnado más pequeño por lo que puede ser útil en las aulas infantiles" (INF _ 51).

No obstante, el análisis de este valor arroja datos positivos:

- De la primera pregunta del ámbito educativo, "La inclusión de memes en la asignatura de LIFL me ha abierto nuevas líneas para fomentar la lectura", observamos que un 33,1 \% de los informantes señala el ítem 4 (bastante de acuerdo). Además, destacamos algunas justificaciones muy positivas a las respuestas, como por ejemplo: "Considero que los memes en ocasiones son necesarios ya que nos permiten hacer un breve resumen del contenido de forma divertida o llamativa que hace captar la atención de la persona que lo está viendo" (INF _ 26); "Nunca pensé que un meme que, quizás lo utilizamos los adultos para reírnos sobre algún tema en concreto, nos sirviese para llevar la lengua y la lectura y literatura a las aulas de Educación Infantil. Creo que es interesante que se haga este tipo de iniciativas para poder llegar al alumnado de una manera más lúdica y divertida" (INF_ 119). Pese a que, en general, las respuestas son positivas conforme al uso de memes en la asignatura, algunas de las respuestas muestran negatividad, sobre todo con respecto a las estrategias que se seguirían al usar la memética en clase: "He entendido los memes de la asignatura como material para poder comprenderla y ampliar nuestro aprendizaje, pero no sabría cómo usar un meme para fomentar la lectura en la educación infantil" (INF _ 98); "Puede ser un buen método para que los niños alcancen el lenguaje humorístico y entiendan todo lo que engloba, pero no sabría cómo enfocarlo" (INF_ 33).

- De la segunda cuestión, “Como futuro docente, usaría memes en mis clases", el resultado con tendencia al alza positivo lo encontramos también en la escala 4 (bastante de acuerdo). No obstante, en las justificaciones la mayoría de las respuestas se centran en la dificultad de usarlos con el alumnado de Educación Infantil, aunque encontramos respuestas en las que los futuros docentes muestran el ímpetu por ponerse a prueba: "En la dificultad está la oportunidad. Será todo un reto lleno de beneficios para el alumnado y para mí como docente, quién sabe" (INF _ 51); "Los usaría dependiendo del tema y adaptándolos a la edad. También me podría ayudar a despertar el interés por la lectura del alumnado, ya que al ser un soporte actual llama más la atención" (INF_ 22).

- En la tercera pregunta, "Pienso que se puede fomentar la lectura a partir de un meme", el resultado mayor al alza, también se registra en el nivel 4, con un 39,1 \%. De las justificaciones del alumnado encuestado, encontramos respuestas muy reveladoras, como por ejemplo, "En los memes se establecen relaciones de intertextualidad y puede ser motivante" (INF _ 24), reflejando esta una relación entre la teoría vista en clase (desarrollo de la competencia literaria e intertextualidad) y la memética -Figura 6- 
Figura 6

Resultados de "La inclusión de memes en la asignatura de LIFL me ha abierto nuevas líneas para fomentar la lectura"'”; "Como futuro docente, usaría memes en mis clases" y "Pienso que se puede fomentar la lectura a partir de un meme"

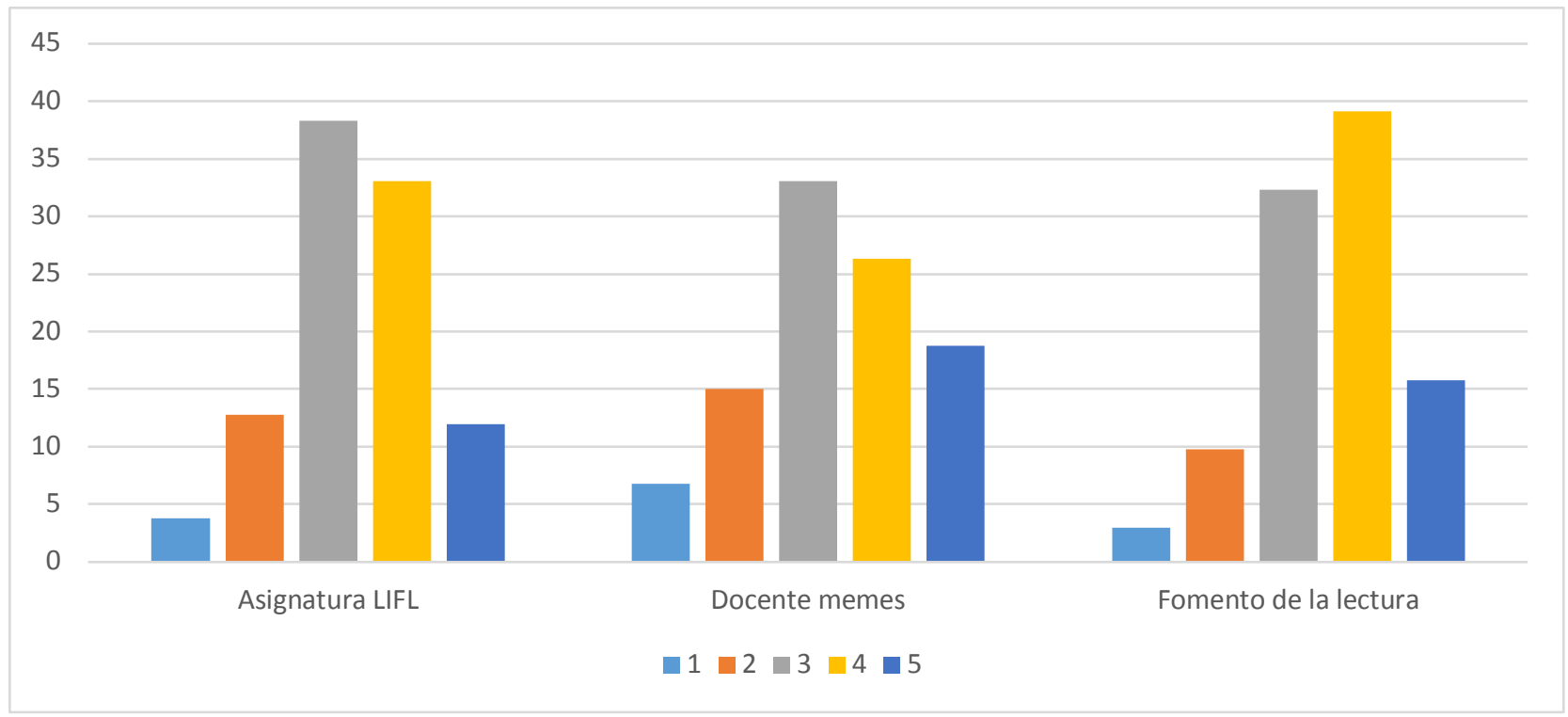

Fuente: Realización propia

\subsection{Valor 5: Relaciones de intertextualidad literaria y cultural de los memes y disfrute}

\subsubsection{Meme 1 .}

Figura 7

Meme 1 literario para el estudio

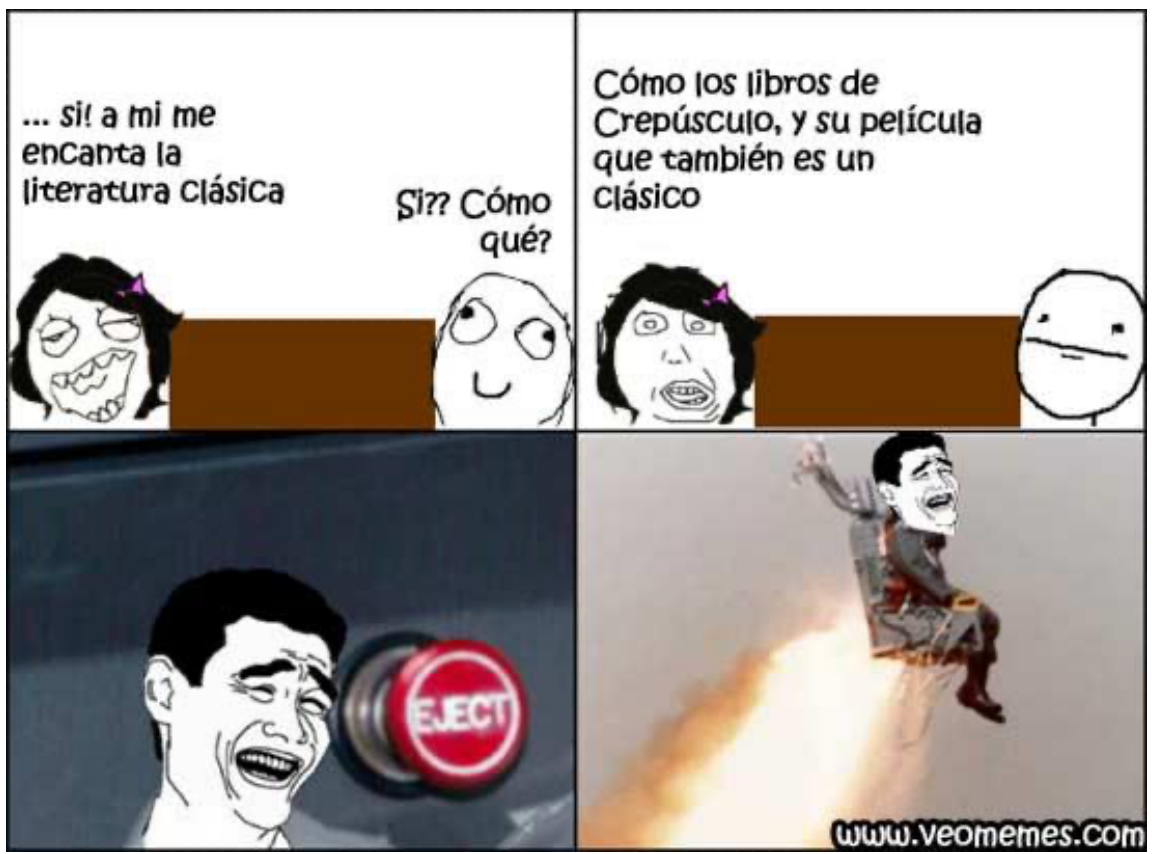

Fuente: Página de memes Memedroid, https://es.memedroid.com/memes/detail/183686

Los resultados en torno a las referencias culturales e intertextuales de este primer meme, revelan algunas evidencias interesantes: por una parte, el $41,4 \%$ de los informantes responden de una manera en la que no se aprecia una relación clara con el hipotexto, es decir, no refleja una cultura literaria en la que el meme le dé pie a llegar a reflexiones sobre la literatura clásica y la cuestión de la mass culture, reflejados en este caso en la saga 
Crepúsculo, sino que esta mayoría de alumnado tiende a parafrasear lo que dice el meme. Por otra parte, el 32,7 $\%$, aunque refleja una cultura literaria superior a los anteriores, siguen sin ofrecer una respuesta clara; no obstante, el $21,3 \%$, hace un ejercicio correcto de intertextualidad a la hora de interpretar el meme, incluso relacionándolo con conceptos vistos en la asignatura durante el semestre (educación literaria, competencia literaria, etc.) -Figura 8-.

\section{Figura 8}

Resultados de ¿Qué te ha sugerido este meme? Puedes hacer referencia a cualquier cuestión cultural o no que se te ocurra

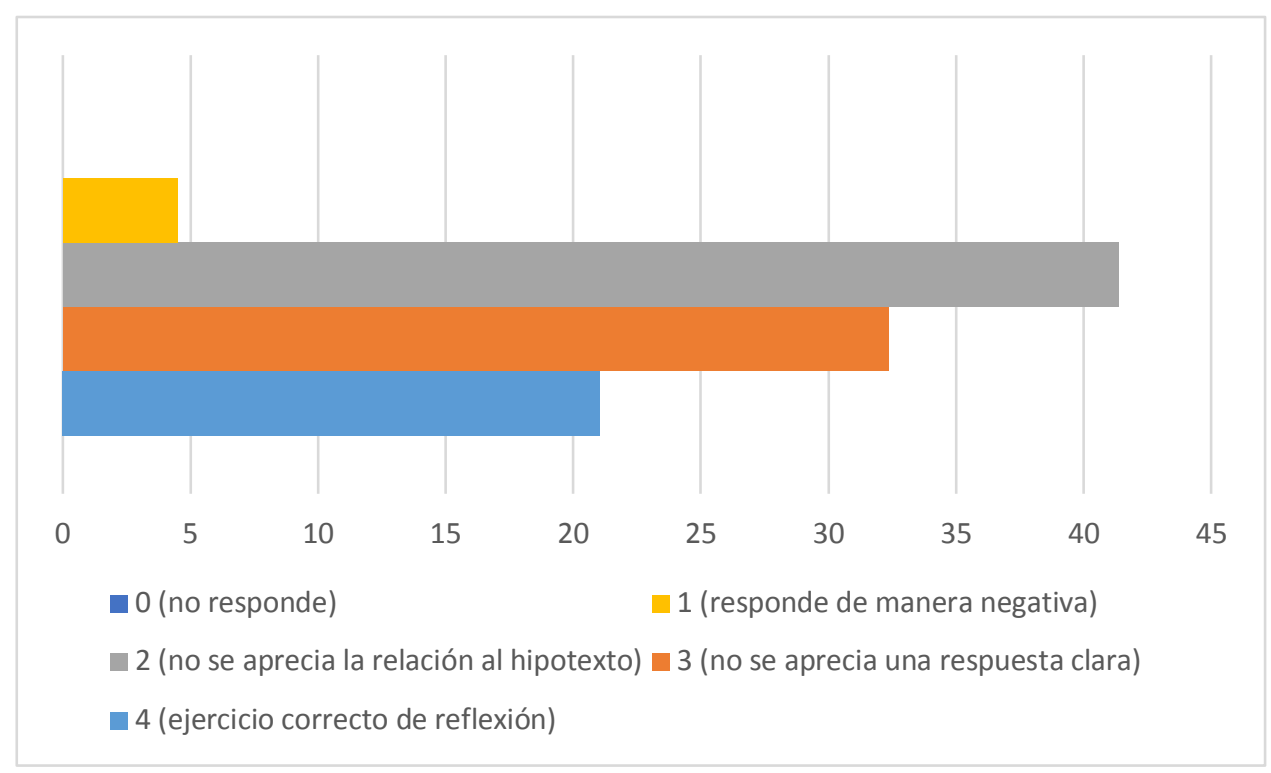

Fuente: Realización propia

Algunas de las aseveraciones del alumnado son: "Pienso que al decir literatura clásica, el otro personaje lo ha malinterpretado, ya que se refería a otro término. El personaje considera como clásico, aquello que suele ser conocido por muchas personas, y en este caso, no se refiere a ello" (INF _ 58); "Sinceramente me viene a la mente que no se tiene conocimiento de lo que es realmente un clásico, sino que se considera clásico a aquello que tiene fama" (INF_ 18); "Catalogar a crepúsculo como literatura clásica no tiene ningún sentido. Ojo, que me gusta crepúsculo, pero sería incapaz de decir que es clásico" (INF _ 17); "Ese meme es muy antiguo, tiene razón por el hecho de que Crepúsculo no es un clásico, pero se usaba para reírse de las mujeres que leían ese tipo de libros, como si fuésemos tontas" (INF_ 125).

Tras el análisis de este primer meme con respecto al plano de la intertextualidad cultural y literaria, nos detendremos en el plano del disfrute. En este caso, los resultados están muy polarizados entre la escala "bastante" (42,1 \%) y "poco" (39,1\%). En este sentido, solo un 7,5 \% señala el índice "mucho" -Figura 9-. 
Figura 9

Resultados de "Tras este meme,

puedo decir que he disfrutado"

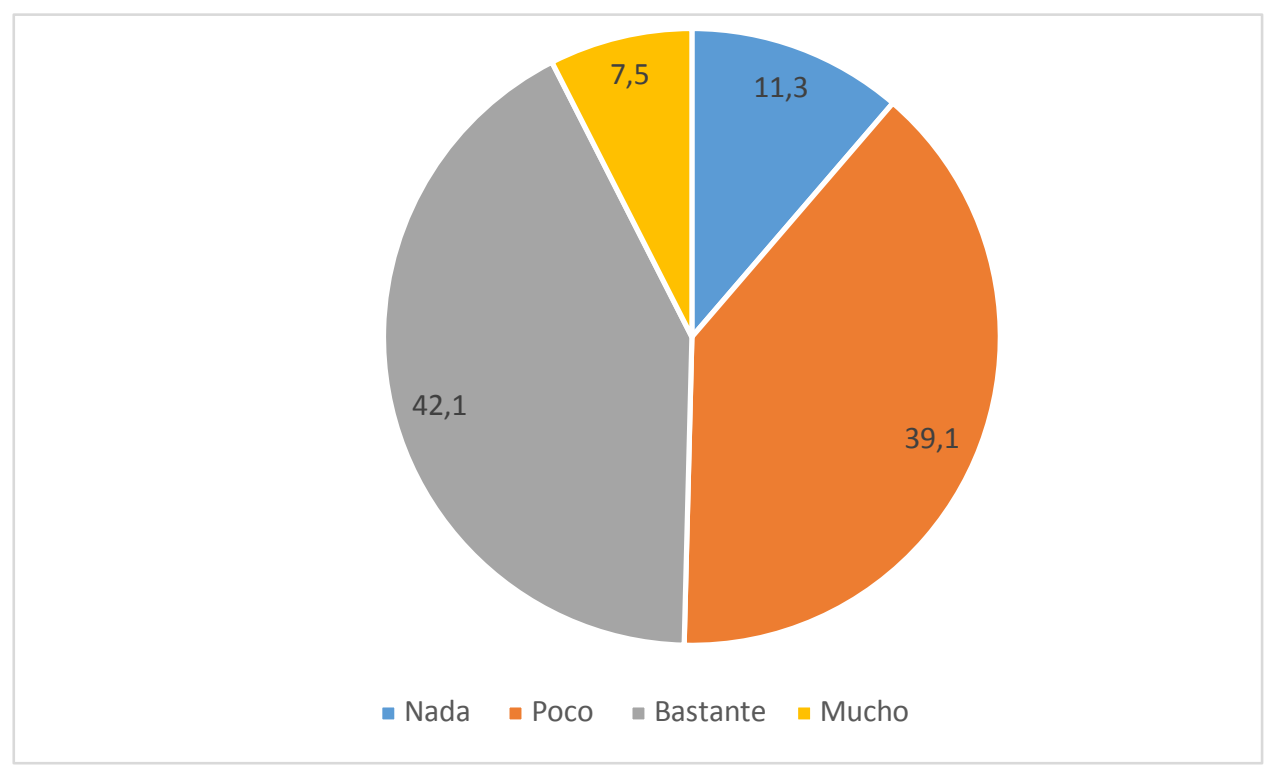

Fuente: Realización propia

\subsubsection{Meme 2}

Figura 10

Meme 2 literario para el estudio

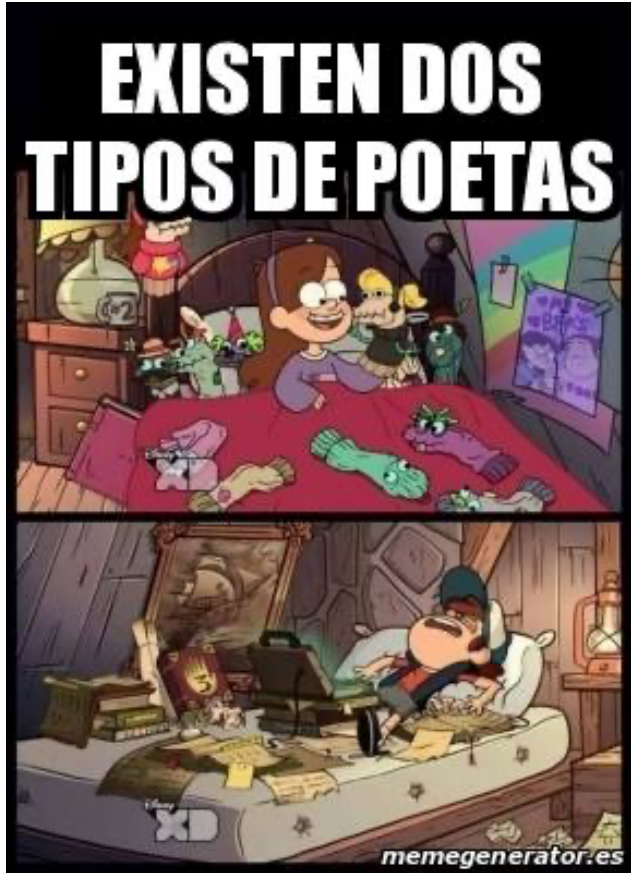

Fuente: Página de Facebook Memes literarios, https://www.facebook.com/MemeLiterario 
Con respecto al segundo meme que ofrecimos en su relación con las conexiones culturales y textuales, los resultados se concentran en las cuatro primeras categorías; no obstante, destacamos el $29,3 \%$ de los informantes que señalan una respuesta que refleja una cultura literaria, aunque sn apreciarse una respuesta clara en relación con el meme. Por otra parte, también destacamos el 26,3 \% que manifiesta una actitud negativa y en cuyas respuestas se reitera el no lo entiendo -Figura 11-.

\section{Figura 11}

Resultados de ¿Qué te ha sugerido este meme? Puedes hacer referencia a cualquier cuestión cultural o no que se te ocurra

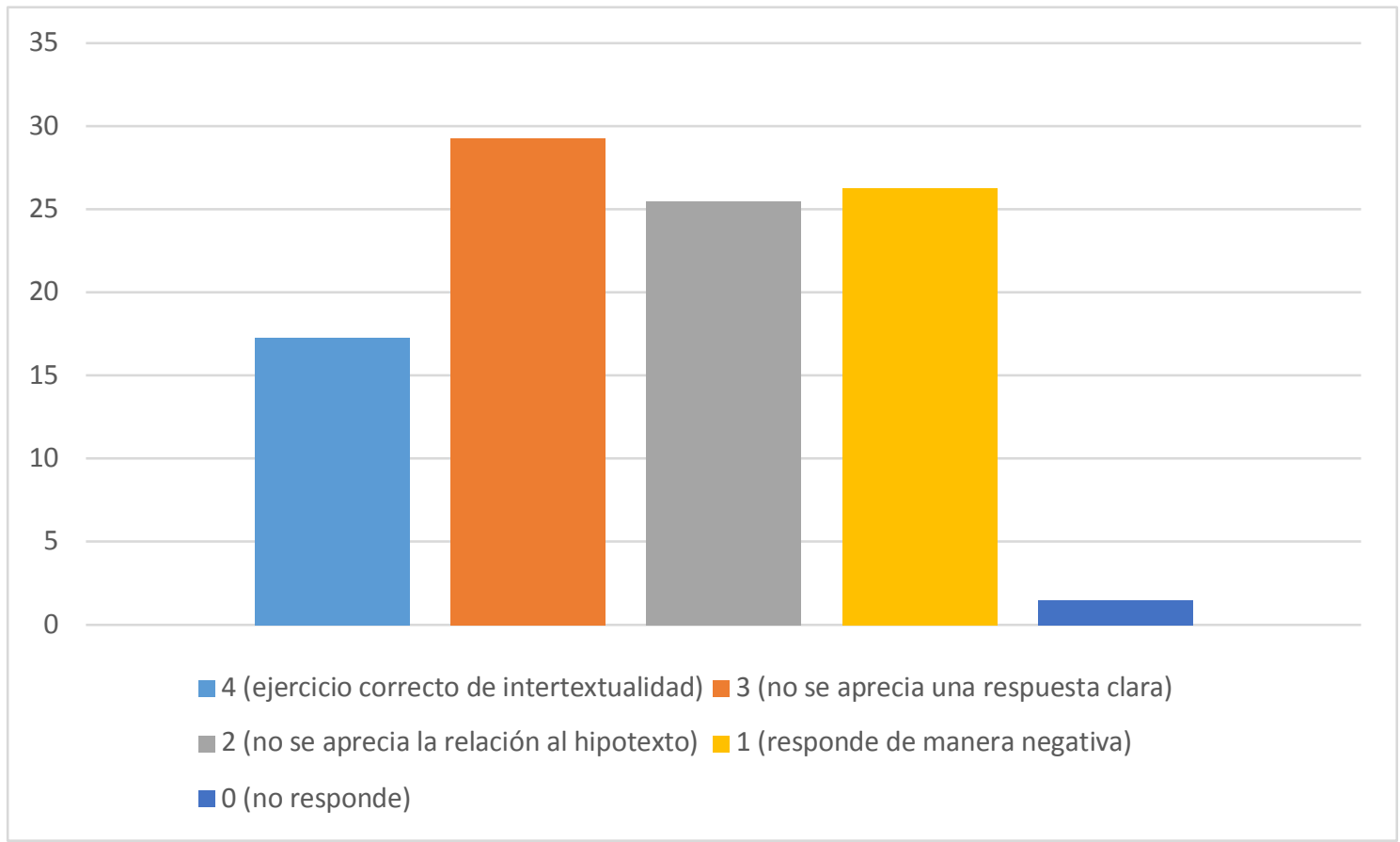

Fuente: Realización propia

Algunas respuestas del alumnado son: "Creo que hace referencia a los dos tipos de poetas que existen en la actualidad, es decir, los modernos de ahora que ya a cualquiera se le llama poeta o los poetas de hace unos siglos cuyas palabras contaban historias" (INF_ 29); "El contraste entre tipos de personas, alguna que viven más en un mundo imaginado y otros en el mundo real".

Con respecto al plano del disfrute, las respuestas siguen el hilo de lo que hemos vislumbrado en el plano de las relaciones intertextuales y culturales. En este sentido, solo el 4,5\% indica haber disfrutado mucho (resultado parecido en el plano del disfrute del primer meme) y el 38,3\% afirma haber disfrutado poco, un resultado negativo que se constata con el $27,8 \%$ que expresa haber disfrutado nada -Figura $12-$ 
Figura 12

Resultados de "Tras este meme, puedo decir que he disfrutado"

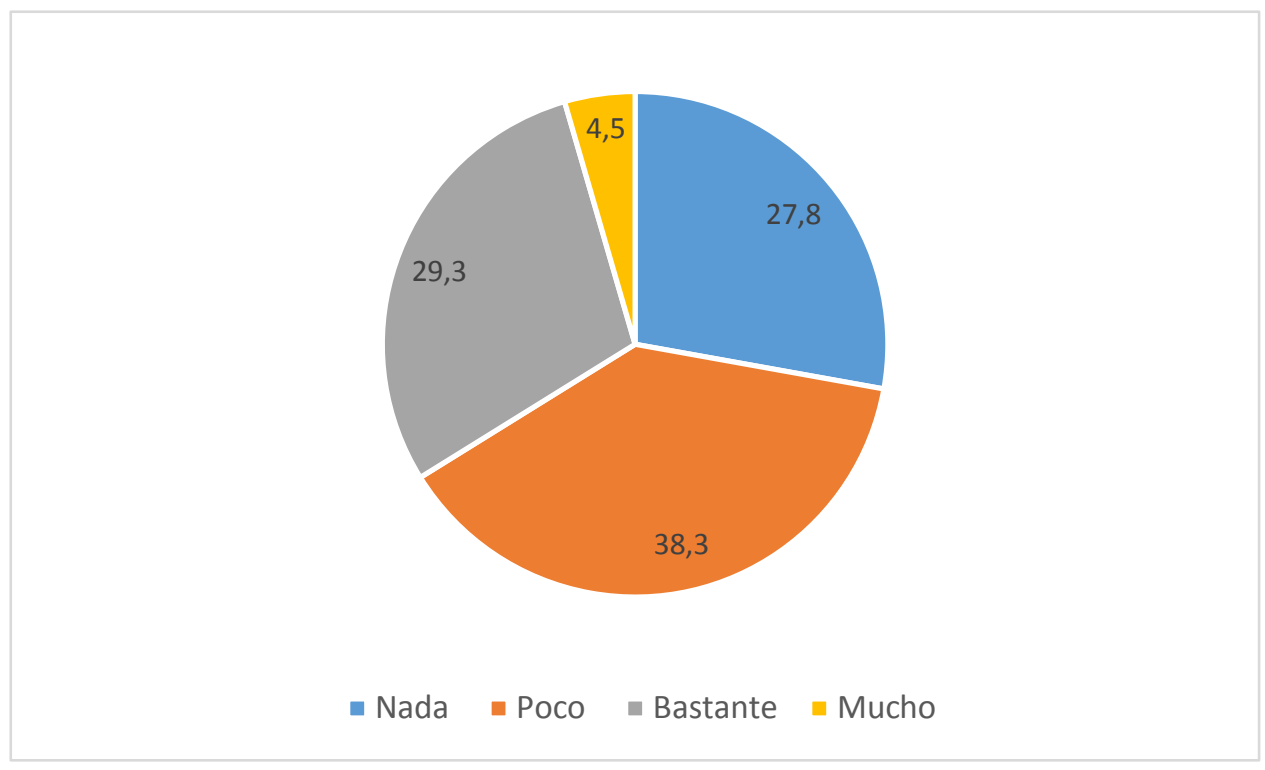

Fuente: Realización propia

\section{Conclusiones}

Como planteábamos en la introducción, los memes se han incorporado a nuestra vida diaria y no ha sido menos en el ámbito educativo. Según Boa Sorte (2019):

In the classroom, teachers can take advantage of such a long-standing and substantial phenomenon. Internet memes are massively incorporated into the students' daily lives, and can be easily accessed or produced by a couple of touches on the cell phone screen. They are part of the digital culture in which we are inescapable immersed (p. 52).

Y es que, como también apunta el autor, todo se puede convertir en un meme (Boa Sorte, 2019). La cercanía y accesibilidad de esta nueva vía de comunicación abierta, nos pareció un gran punto de partida para realizar esta investigación.

A continuación, nos detendremos en las hipótesis que propusimos con respecto a las dimensiones establecidas para determinar algunas conclusiones de nuestro estudio.

En primer lugar, proponíamos como hipótesis de la dimensión "Autoconcepto como lector y uso de plataformas y lecturas digitales" que, pese a que el alumnado prefiere la lectura en papel, hace uso de las redes sociales y comparte memes de manera asidua, hipótesis que ha quedado confirmada con los datos. Pese a que los resultados son negativos en relación con la lectura en formatos digitales, estos cambian radicalmente con respecto a la pregunta de si comparten memes en los usos sociales en los que participan (por ejemplo, en las redes sociales), de lo que desgranamos que estos informantes no hacen uso de la lectura en medios digitales, pero sí conforme a su presencia en las redes sociales. Remitiremos a las palabras de Álvarez, Heredia y Romero (2019), quienes hacen hincapié en el carácter social del uso de las redes sociales en un carácter comunicativo e, incluso, lúdico, como ocurre con estos maestros en formación inicial. 
Con respecto a la segunda dimensión que planteamos, "Competencia literaria, disfrute y relaciones intertextuales de los memes literarios", hemos constatado la hipótesis que propusimos. En este sentido, observamos una polarización en los resultados que indica que la competencia literaria del alumnado no está desarrollada como debiera, ya que, en el proceso de interacción con los memes literarios, no se decodifican los hipotextos e hipertextos. En líneas generales, la cultura literaria de los informantes no está tan consolidada como nos hubiera gustado descubrir; esto no sería un problema en otro ámbito (solo un problema de cultura general), no obstante, estos resultados tan bajos son preocupantes debido a la naturaleza del alumnado, maestros en formación inicial.

En la segunda parte de la hipótesis, hicimos hincapié en que las dificultades de acceso al disfrute de los memes es menor por sus carencias en el reconocimiento de relaciones del intertexto lector y del intertexto cultural. A este respecto, verificamos que hay también una polarización entre la activación de conocimientos, ideas y experiencias previas, sintiéndose este alumnado en conexión con la lectura, mientras que otra gran mayoría no disfruta de la lectura, ya que mantiene una actitud negativa hacia esta. Esta distensión puede tener una respuesta en la primera pregunta del cuestionario, en la que solo un 18,8 \% admitió leer "mucho" y un amplio 36,8 \% expresó leer "algo".

A este respecto, podemos afirmar que la lectura y la cultura literaria han cambiado y ya no hay vuelta atrás. En este cambio, encontramos una gran cantidad de estrategias, la mayoría de ellas multimedia, en las que cultura, literatura y distintos multiversos hipermediales se encuentran para ofrecer a este nuevo lector otras vías de acceder al texto; en nuestro caso, ofrecemos los memes como un ejercicio hipermedial que permite tanto al lector habitual, como al lector en ciernes, establecer un diálogo literario actualizado.

\section{Referencias bibliográficas}

Álvarez, E.; Heredia, H. y Romero, M. (2019). La Generación Z y las Redes Sociales. Una visión desde los adolescentes en España. Revista Espacios. 40(20), pp. 9-21. Recuperado de: https://www.revistaespacios.com/a19v40n20/a19v40n20p09.pdf.

Beltrán Pellicer, P. (2016). Utilizando memes con tus alumnos. Números. Revista de didáctica de las matemáticas, 91, pp. 129-134.

Boa Sorte, P. (2019). Internet memes: clasroom perspectives in the context of digital cultures. Educaçao \& formaçao, 4(12), p. 51-66.

Contín, S. (2011). Las nuevas alfabetizaciones: más allá de la alfabetización tradicional en Argentina. Lenguaje y Textos, 34, pp. 47-56.

Chaverra, D (2008). La actividad metacognitiva durante la producción de un texto hipermedial. Lectura y vida: Revista latinoamericana de lectura, 29(4), pp. 30-42

Dawkins, R. (1989). The selfish gene

Hernández Sampieri, R., Fernández Collado, C. y Baptista Lucio, P. (2007). Fundamentos de metodología de la investigación. Madrid: McGraw-Hill, Interamericana de España.

Lomas, C. (1999). Cómo enseñar a hacer las cosas con las palabras: teoría y práctica de la educación lingüística. Barcelona: Paidós.

Mulato, A. (2016). Solo entenderás estas bromas si te gusta la literatura. Verne. El País. 
Munita, F. (2013). Creencias y saberes de futuros maestros (lectores y no lectores) en torno a la educación literaria. Ocnos, 9, pp. 69-87.

Munita, F. (2016). Prácticas didácticas, creencias y hábitos lectores del profesor en una escuela exitosa en la promoción lectora. Ocnos, 15 (2), 77-97.

Pérez Tornero, J.M. (2000). Comunicación y educación en la sociedad de la información, Barcelona: Paidós.

Prado, J. (2011). Didáctica de la Lengua y la Literatura para educar en el siglo XXI. Madrid: La Muralla.

Romero, M. F., y Jiménez, R. (2014). El prácticum del MAES y la formación inicial en la enseñanza de lenguas: entre la realidad y el deseo. Lenguaje y Textos, 39, pp. 49-58.

Romero, C., y Jiménez, R. (2019): La formación inicial del máster de profesorado: reflexiones en torno a la implementación de una propuesta didáctica para una educación lecto-literaria. Investigaciones Sobre Lectura, 12, pp. 1-18.

Romero, M. F., y Trigo, E. (2018). Entre las creencias y la formación inicial de los estudiantes del Máster de Profesorado de Secundaria: una mirada hacia la enseñanza de la literatura en las aulas. Profesorado, Revista de Currículum y Formación del Profesorado, 22(1), pp. 89-112.

Tabernero, R. (2007): Intertextualidad heterorreferencial: una vía para la formación del lector literario. Lenguaje y textos, 26, pp. 53-62.

Esta obra está bajo una Licencia Creative Commons

Attribución-NoCommercial 4.0 International

\section{(cc) EY-NG}

